\title{
A New Record of Micromus angulatus (Neuroptera: Hemerobiidae) from Korea
}

\author{
Tae-Ho Kim ${ }^{1}$, Seung-Ho Oh${ }^{2}$, Young-Ho Kim ${ }^{1}$ and Jong-Chul Jeong ${ }^{3, *}$ \\ ${ }^{1}$ Beneficial Insect Research Institute, Sesil Corporation, Nonsan 320-833, Korea \\ ${ }^{2}$ Department of Biology, Yeungnam University, Gyeongsan 712-749, Korea \\ ${ }^{3}$ National Park Research Institute, Jucheon-myeon, Namwon-si, Jeollabuk-do 590-811, Korea
}

\begin{abstract}
We report one hemerobiid species, Micromus angulatus (Stephens, 1836), for the first time in Korea. Diagnosis and photographs of the species are provided.
\end{abstract}

Keywords: taxonomy, Hemerobiidae, Microminae, Micromus angulatus, Korea

\section{INTRODUCTION}

The genus Micromus is one of most diverse hemerobiid brown lacewing in the world. This genus contains 85 species with one Korean species (M. numerosus) erected by Rambur (1842) for Hemerobius variegates Fabricius, 1793. Morphologically, Micromus is easily distinguished from other hemerobiid genera by combination of following characteristics: five segmented maxillary palpi and three segmented labial palpi; forewing with costal area quite narrow at base, and one prestigmal Sc-R crossvein, without recurrent humeral vein and crossvein 2M-Cu (Oswald, 1993). Members of genus Micromus are generally considered to be beneficial as predators of various aphids, particularly on sugar cane and corn plants (Williams, 1927). They occur in a variety of habitats including both trees and grasses (Carpenter, 1940). In this report, we describe Micromus angulatus (Stephens) new to Korea with diagnosis, illustrations of diagnostic characters and distributional data, and provide key to two Korean species of Micromus.

All the material used in this work was collected by light trap and sweeping, and deposited in the Beneficial Insect Research Institute of the Sesil Corporation. The morphological terminologies followed those of Makarkin (1994) and Oswald (1993). Specimens were examined with stereomicroscope (Nikon SMZ1500; Nikon, Melville, NY, USA). Digital images were produced with a Delta imaging system (i-Delta 2.6; iMTechnology, Daejeon, Korea). Abbreviations for type information are as follows: TS, Type species; TL, Type Locality; TD, Type Depository. Abbreviations for museums

*To whom correspondence should be addressed

Tel: 82-63-625-7654, Fax: 82-63-625-7657

E-mail: incence@yumail.ac.kr and institutions are: BISC, Beneficial Insect Research Institute, Sesil Corporation, Nonsan, Korea; BMNH, The Natural History Museum, London, UK; ISNB, Institut Royal des Sciences Naturelles de Belgique, Bruxelles, Belgium; MNHP, Morristown National Historical Park Virtual Museum, Morristown, USA; MZUN, Museum of Zoology, Navarra University, Pamplona, Spain; NHMW, Naturhistorisches Museum, Vienna, Austria; UZIL, Universitetets Zoologiska Institution, Lund, Sweden.

\section{SYSTEMATIC ACCOUNTS}

Order Neuroptera

Superfamily Hemerobioidea

Family Hemerobiidae Latreille, 1802

${ }^{1 *}$ Subfamily Microminae Krüger, 1822

2*Genus Micromus Rambur, 1842

Micromus Rambur, 1842: 416. TS: Hemerobius variegates Fabricius, 1793.

Key to the species of the genus Micromus in Korea

1. Body length $12-16 \mathrm{~mm}$. Forewing with 2-3 transversefasciae; Rs with 4 (female) or 5 (male) branches ......... M. angulatus (Stephens)

- Body length 15-20 mm. Forewing without transversefasciae; Rs with 7 or rarely 8 branches

M. numerosus (Navás)

\footnotetext{
${ }^{3 *}$ Micromus angulatus (Stephens, 1836) (Fig. 1A-F)

Hemerobius angulatus Stephens, 1836: 106. Type: female, TL: unknown, TD: BMNH.

Hemerobius villosus Zetterstedt, 1840: 1050. Type: unknown,
} 

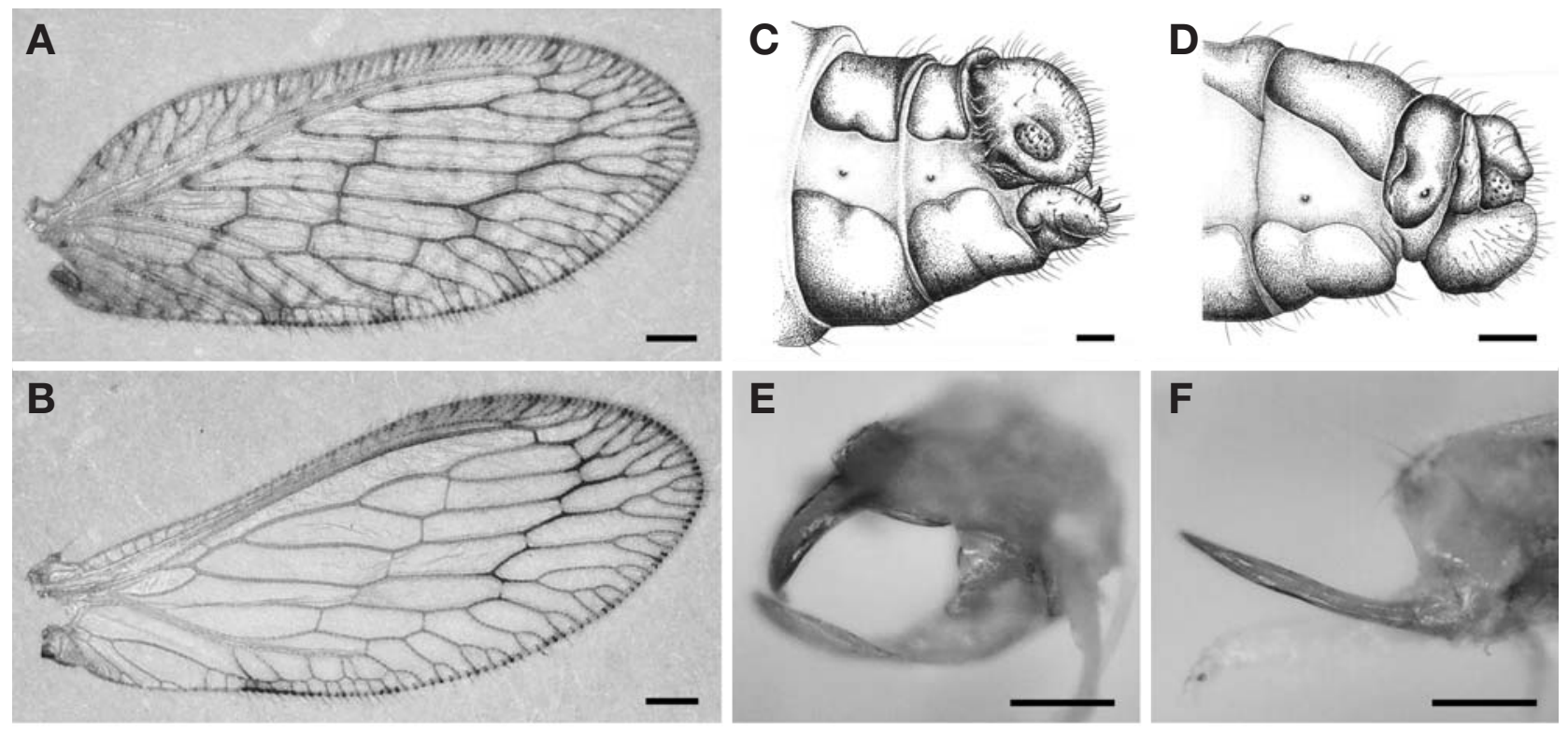

Fig. 1. Micromus angulatus, male. $A$, Forewing in right; $B$, Hindwing in right; $C$, Apex of abdomen, lateral view; $E$, Gonalcus and parameres, lateral view; F, Catoprocessus, lateral view; female. $D$, Apex of abdomen, lateral view. Scale bars $=0.5 \mathrm{~mm}(A, B), 0.25 \mathrm{~mm}$ $(C, D), 0.12 \mathrm{~mm}(\mathrm{E}, \mathrm{F})$.

TL: unknown, TD: UZIL.

Hemerobius intricatus Wesmael, 1841: 214. Type: unknown, TL: Belgium (Brussels), TD: ISNB.

Hemerobius tendinosus Rambur, 1842: 417. Type: unknown, TL: Italia (Sardinia), TD: MNHP.

Hemerobius lineatus Göszy, 1852: 345. Type: unknown, TL: unknown, TD: NHMW.

Mucropalpus meridionalis A. Costa, 1863: 31. Type: male, TL: Italia (Reggio di Calabria), TD: MZUN.

Micromus jonas Needham, 1905: 15. Type: unknown, TL: USA (New York), TD: unknown.

Micromus theryanus Navás, 1910: 72. Type: unknown, TL: Argeria (Philippeville), TD: MNHP.

Material examined. $3 \sigma^{7} 3$ 우, Korea: Chungcheongnam-do Province, Nonsan, Yeonmu-eup, Dongsan-ri, 11 May. 2009 (T.H. Kim). $1 \mathrm{o}^{7} 4$ 우, Korea: Chungcheongnam-do Province, Nonsan, Beolgok-myeon, 14 Jun. 2009 (T.H. Kim). $7 \sigma^{7}$, ditto, 24 Jun. 2009 (T.H. Kim). $5 \sigma^{7} 2$ 우, Jeollabuk-do Province, Iksan, Palbong-dong, 5 Jul. 2009 (T.H. Kim).

Diagnosis. Body length about 12.0 to $16.0 \mathrm{~mm}$. Forewing length about 6.0 to $6.8 \mathrm{~mm}$.

Coloration. Body largely light brown. Face, genae and vertex light yellow. Antennae and palpi pale brown. Pronotum with large dark brown spot on ventroposterior corner. Median part of metanotum light brown and posterior part dark brown. Legs light brown darker apically. Forewing membrane brown; maculations covers gradate series and small patches scattered all over membrane. Hindwing hyaline.

Venation. Forewing. Between basal branches of Sc without crossveins. One apical crossvein present between $\mathrm{Sc}$ and R1. Rs with 4 (female) or 5 (male) branches, and Rs4 with secondary branches. Between $\mathrm{M}$ and $\mathrm{Cu}$, with distinct crossvein (female) or faint crossvein (male). $\mathrm{CuP}$ arising from basal part of $\mathrm{CuA}$. Inner gradate series with 2 crossveins (male with 2). Intermediate gradate series with 5-6 (female) or 5-6 (male) crossveins. Outer gradate series with 5-7 (female) or 5-7 (male) crossveins.

Hindwing. One apical crossvein present between Sc and R1. Rs with 4 branches. $r$ vein present. Inner crossvein absent. Intermediate gradate series with 5 crossveins, the cossveins rs2-rs1 and rs1-m interrupted or incomplete. Outer gradate series with 7 crossveins, crossveins interrupted or incomplete.

Male genitalia. Ectoproct with moderately long catoprocessus which is, anterioly curved and hooked. Callus cerci with about 13 trichobothria. Sternite IX in lateral view small and triangular in shape, extending beyond ectoproct apex. Arcessus smooth, and hook-like directed ventrally. Parameres smooth, moderately stout, translucent, fused anteriorly, with projection directed upwards, and evenly curved.

Distribution. Palaearctic region, Nearctic region and Neotropical region.

Remarks. The male easily distinguished from other species of the genus by the shape of genitalia, which has a bented anteriorly catoprocessus. 


\section{ACKNOWLEDGEMENTS}

We thank to Dr. Shigehiko Tsukaguchi (Nishinomiya, Japan) for the help in identifying species and Mr. Sung-Kwon Jang for providing valuable reprints. We also thank Mrs. Jin-Kyung Choi for stimulating talks of morphology and useful comments on this paper.

\section{REFERENCES}

Aspöck, H., U. Aspöck and H. Hölzel, 1980. Die Neuropteren Europas. Goecke and Evers, Krefeld, 1: 1-495.

Carpenter, F.M., 1940. A revision of the Nearctic Hemerobiidae, Berothidae, Sisyridae, Polystoechotidae and Dilaridae (Neuroptera). Proc. Amer. Acad. Arts Sci., 74: 193-280.

Hagen, H.A., 1886. Monograph of the Hemerobiidae. Part II [Micromus]. Proc. Bost. Soc. N. H., 23: 276-292.

Killington, F.J., 1936. A monograph of the British Neuroptera,
Monograph of the Royal Entomological Society, London, pp. 1-270.

Kuwayama, S., 1962. A revisional synopsis of Neuroptera in Japan. Pacific Insects, 4(2): 325-412.

Makarkin, V.N., 1994. The Oriental Hemerobiidae (Insecta: Neuroptera) described by Waro Nakahara. Raffles Bull. Zool., 42(4): 917-926.

Nakahara, W., 1960. Systematic studies of the Hemerobiidae (Neuroptera). Mushi, 34(1): 1-69.

Navás, L., 1910. Hémérobides nouveaux du Japon (Neroptera). Rev. Russ. Entom., 4: 295-398.

Oswald, J.D., 1993 Revision and cladistic analysis of the world genera of the family Hemerobiidae (Insecta: Neuroptera). J.N.Y. Entomol. Soc., 101: 143-299.

Rambur, M.P., 1842. Histoire naturelle des Insectes. Néuroptères. Roret, Paris, pp. 1-534.

Williams, F.X., 1927. The brown Australian lacewing (Micromus vinaceus). Hawaii. Pl. Rec., 31: 246-249.

Received May 31, 2010 Accepted July 8, 2010 